University of South Florida

DIGITAL COMMONS

Digital Commons @ University of

@ UNIVERSITY OF SOUTH FLORIDA

South Florida

2-13-2007

\title{
High Crystallinity Si-Ferrihydrite: An Insight Into Its Neel Temperature and Size Dependence of Magnetic Properties
}

\author{
Thelma S. Berquo \\ University of Minnesota \\ Subir K. Banerjee \\ University of Minnesota \\ Robert G. Ford \\ National Risk Management Research Laboratory, Ada, Oklahoma \\ R. Lee Penn \\ University of Minnesota \\ Thomas Pichler \\ University of South Florida, pichler@usf.edu
}

Follow this and additional works at: https://digitalcommons.usf.edu/gly_facpub

Part of the Geochemistry Commons, Geology Commons, and the Geophysics and Seismology Commons

\section{Scholar Commons Citation}

Berquo, Thelma S.; Banerjee, Subir K.; Ford, Robert G.; Penn, R. Lee; and Pichler, Thomas, "High Crystallinity Si-Ferrihydrite: An Insight Into Its Neel Temperature and Size Dependence of Magnetic Properties" (2007). Geology Faculty Publications. 12.

https://digitalcommons.usf.edu/gly_facpub/12

This Article is brought to you for free and open access by the Geology at Digital Commons @ University of South Florida. It has been accepted for inclusion in Geology Faculty Publications by an authorized administrator of Digital Commons@ @niversity of South Florida. For more information, please contact digitalcommons@usf.edu. 


\title{
High crystallinity Si-ferrihydrite: An insight into its Néel temperature and size dependence of magnetic properties
}

\author{
Thelma S. Berquó, ${ }^{1}$ Subir K. Banerjee, ${ }^{1}$ Robert G. Ford, ${ }^{2}$ R. Lee Penn, ${ }^{3}$ \\ and Thomas Pichler ${ }^{4}$ \\ Received 20 June 2006; revised 27 September 2006; accepted 6 October 2006; published 13 February 2007.
}

[1] Ferrihydrite, an antiferromagnetic iron oxyhydroxide with resulting magnetization due to uncompensated spins, is of great importance for the cycling of many trace metals in the environment. Four ferrihydrite samples prepared with 1.3 to $3.5 \mathrm{wt} \%$ of $\mathrm{Si}$ at different synthesis temperatures $\left(7.5^{\circ} \mathrm{C}, 22^{\circ} \mathrm{C}, 50^{\circ} \mathrm{C}\right.$, and $\left.75^{\circ} \mathrm{C}\right)$ were studied by temperaturedependent hysteresis loops, ZFC/FC susceptibility curves, ac susceptibility and Mössbauer spectroscopy. The incorporation of Si into the ferrihydrite during synthesis changed the properties of this mineral. Interestingly, seven sharp lines were observed in the X-ray diffraction pattern of the ferrihydrite samples prepared at $50^{\circ} \mathrm{C}$ and $75^{\circ} \mathrm{C}$.

In general, both XRD and magnetism demonstrate that particle size decreased (from $23 \mathrm{~nm}$ to $2 \mathrm{~nm}$ ) and particle size distribution narrowed as the synthesis temperature was lowered. Those samples prepared between $7.5^{\circ} \mathrm{C}$ and $50^{\circ} \mathrm{C}$ showed the expected superparamagnetic behavior of ferrihydrite below $300 \mathrm{~K}$. The ferrihydrite prepared at $75^{\circ} \mathrm{C}$ was unusually coarse-grained and had a blocking temperature above $300 \mathrm{~K}$. Extrapolation of induced magnetization from the largest particles with the highest crystallinity allowed an estimate of a ferrihydrite Néel temperature of around $422 \mathrm{~K}$. We also present XRD and magnetic data from large natural Si-ferrihydrite collected from a marine shallow-water hydrothermal area that formed at a temperature of approximately $88^{\circ} \mathrm{C}$.

Citation: Berquó, T. S., S. K. Banerjee, R. G. Ford, R. L. Penn, and T. Pichler (2007), High crystallinity Si-ferrihydrite: An insight into its Néel temperature and size dependence of magnetic properties, J. Geophys. Res., 112, B02102, doi:10.1029/2006JB004583.

\section{Introduction}

[2] The study of ferrihydrite is of great interest for its importance in the biogeochemical cycling of iron and associated trace elements and for its apparent role in recording geophysical processes in a range of natural environments. This naturally occurring hydrated ferric oxyhydroxide can be found in a wide variety of different environments such as sediments, mine wastes, acid mine drainage, soils [Jambor and Dutrizac, 1998], Mars surface samples [King and McSween, 2005], and as a precursor of fine-grained magnetic particles in Chinese paleosols [Liu et al., 2005]. It typically occurs as a disordered fine grained nanophase, and it is a common and important constituent of many soils. However, its identification is difficult due to the presence of other minerals and its poor crystallinity. Like other iron oxides it is a strong pigment and can influence many soil properties [Childs, 1992].

\footnotetext{
${ }^{1}$ Department of Geology and Geophysics, Institute for Rock Magnetism, University of Minnesota, Minneapolis, Minnesota, USA.

${ }^{2}$ U.S. Environmental Protection Agency, National Risk Management Research Laboratory, Ada, Oklahoma, USA.

${ }^{3}$ Department of Chemistry, University of Minnesota, Minneapolis, Minnesota, USA.

${ }^{4}$ Department of Geology, University of South Florida, Tampa, Florida, USA.

Copyright 2007 by the American Geophysical Union. 0148-0227/07/2006JB004583\$09.00
}

[3] In the geochemical cycle, ferrihydrite plays an important role as an adsorber of various trace elements and as a control on the iron cycle in surface waters [Jambor and Dutrizac, 1998]. Rancourt et al. [2001] report the occurrence of ferrihydrite containing high concentrations of arsenic. This material forms in shallow water near submarine hydrothermal vents at Tutum Bay, off the coast of Papua New Guinea. This study further suggests that this As-bearing ferrihydrite has a low degree of crystallinity and that copreciptation of ferrihydrite with As results in retarded particle growth and small particles size. In addition, ferrihydrite is an attractive material for environmental applications due to large surface area, strong adsorptive effects, high adsorption capacity and low cost, and it is often used in processes for treatment and removal of trace elements in wastewaters from various industries [Riveros et al., 2001; Richmond et al., 2004].

[4] Ferrihydrite structure and composition (nominally $\mathrm{Fe}_{5} \mathrm{HO}_{8} 4 \mathrm{H}_{2} \mathrm{O}$; [Fleischer et al., 1975]) is still a subject of debate even though this antiferromagnetic iron phase has been studied by many authors [e.g., Towe and Bradley, 1967; Drits et al., 1993; Janney et al., 2001; Jansen et al., 2002; Seehra et al., 2004] with different techniques. An initial ferrihydrite precipitate is often produced in the laboratory by the rapid hydrolysis of $\mathrm{Fe}^{3+}$ solutions or the slow oxidation of $\mathrm{Fe}^{2+}$ solutions. They are usually designated as "2-line" or "6-line" according to the number of characteristic lines observed in their X-ray diffraction 
(XRD) patterns. Those exhibiting six broad peaks are considered more crystalline, whereas those with only two broad peaks are considered poorly crystalline [Cornell and Schwertmann, 2000]. XRD patterns of natural and synthetic ferrihydrite typically exhibit between two and six broad lines.

[5] There is a paucity of reports regarding the fundamental magnetic properties of ferrihydrite, especially with regards to the magnetic anisotropy constant $(K)$ and the Néel temperature $\left(T_{N}\right)$. In the case of the anisotropy constant, reported data for synthetic ferrihydrite range from 35 to $610 \mathrm{~kJ} / \mathrm{m}^{3}$ [Suzdalev et al., 1996; Harris et al., 1999; Gilles et al., 2000]. $T_{N}$ estimates range from 250 to $500 \mathrm{~K}$ [Gilles et al., 2002; Jansen et al., 2002; Punnoose et al., 2004; Guyodo et al., 2006] and are, in general, found by extrapolation of saturation magnetization or noncompensated magnetization (the magnetization carried by the uncompensated spins) versus temperature data. Some authors, e.g., Pannalal et al. [2005] claim that ferrihydrite saturates in field of less than $1.2 \mathrm{~T}$ and such behavior at room temperature is compatible with a weak ferromagnetic material. Pannalal et al. [2005] further claim that ferrihydrite nanoparticles can act as carriers of Natural Remanent Magnetization.

[6] Ferrihydrite appears to form the core of ferritin, an iron-storage protein of mammals that consists of a hollow, approximately spherical shell of polypeptide with external diameter $12 \mathrm{~nm}$ and internal diameter $8 \mathrm{~nm}$ [Chasteen and Harrison, 1999; St. Pierre et al., 2001]. The majority of previous work aimed at the magnetic characterization of ferrihydrite has used ferritin [Kilcoyne and Cywinski, 1995; Gider et al., 1995; Tejada et al., 1997; Makhlouf et al., 1997; Friedman et al., 1997; Gilles et al., 2000; St. Pierre et al., 2001; Gilles et al., 2002]. Such particles can be considered as an ensemble of magnetically noninteracting particles [Gilles et al., 2000]. In contrast, synthetic samples of ferrihydrite are commonly aggregated, which means that the particles are probably magnetically interacting. This complicates the magnetic characterization of these samples because magnetic dipolar interactions are likely present.

[7] The ferrihydrite found in nature can vary considerably in composition and often contains substantial amounts of coprecipitated silicon. The presence of silicon-bearing ferrihydrite (Si-Fh) in soils is documented by Childs [1992], who has reviewed the available information of XRD and Mössbauer spectroscopy of ferrihydrite. Special attention is also paid to the association between ferrihydrite and $\mathrm{Si}$, and Childs [1992] suggests that natural ferrihydrites from soilrelated environments commonly contain up to $9 \% \mathrm{Si}$. There are still some doubts whether presence of $\mathrm{Si}$ is structural or if it is adsorbed on the surface in natural material [Parfitt et al., 1992]. Anderson and Benjamim [1985] and Campbell et al. [2002] demonstrated the ability of Si to inhibit ferrihydrite transformation to other more stable iron phases like goethite and hematite. Also, Campbell et al. [2002] observed the formation of silicon-bearing hematite as a result of heating Si-containing ferrihydrite at $800^{\circ} \mathrm{C}$. The observation by Campbell et al. [2002] that $\mathrm{Si}$ was structurally incorporated into hematite produced by thermal transformation of $\mathrm{Si}-\mathrm{Fh}$ lead them to conclude that $\mathrm{Si}$ was also structurally incorporated in the precursor ferrihydrite. In contrast, synthetic samples of Si-ferrihydrite were reported by Childs [1992] and Schwertmann et al. [2004] to present an unusual XRD pattern: seven well-defined peaks that are significantly sharper, indicating a greater degree of crystallinity.

[8] Here we present results of the magnetic characterization of four synthetic ferrihydrite samples prepared with 1.3 to $3.5 \mathrm{wt} \% \mathrm{Si}$ by slow oxidation of dissolved $\mathrm{Fe}^{2+}$ at different temperatures $\left(7.5^{\circ} \mathrm{C}, 22^{\circ} \mathrm{C}, 50^{\circ} \mathrm{C}\right.$, and $\left.75^{\circ} \mathrm{C}\right)$ and one natural ferrihydrite sample collected from a marine shallow-water hydrothermal area. XRD patterns of ferrihydrite samples synthesized at temperatures at and above $50^{\circ} \mathrm{C}$ as well as the natural hydrothermal ferrihydrite showed seven sharp lines. These samples have structural features similar to those of the samples described by the authors above. Characteristic magnetic blocking temperatures and distributions of particle size were observed for the $7.5^{\circ} \mathrm{C}$, $22^{\circ} \mathrm{C}, 50^{\circ} \mathrm{C}, 75^{\circ} \mathrm{C}$ and the natural ferrihydrite samples by using low temperature magnetic measurements and ac susceptibility. Additional information was obtained by Mössbauer spectroscopy, which, combined with the methods above, has provided useful information about particle size, size distribution, and inferences regarding Si structural incorporation in ferrihydrite. The Néel temperature for ferrihydrite was also estimated from magnetic measurements performed on the $75^{\circ} \mathrm{C}$ sample.

\section{Material}

\subsection{Synthetic Ferrihydrite}

[9] Silica-bearing ferrihydrite samples were prepared by air oxidation of ferrous iron dissolved in an aqueous medium containing dissolved silica. First, the aqueous medium was prepared by adding the following reagent grade components to one liter of deionized water: $0.0142 \mathrm{~g} \mathrm{KCl}, 0.2084 \mathrm{~g} \mathrm{CaCl}_{2}$, $0.0618 \mathrm{~g} \mathrm{MgSO}_{4}, 0.0708 \mathrm{~g} \mathrm{NH}_{4} \mathrm{HCO}_{3}, 0.1680 \mathrm{~g} \mathrm{NaHCO}_{3}$, $0.1767 \mathrm{~g} \mathrm{Na}_{2} \mathrm{SO}_{4}, 0.2188$ g $2 \mathrm{~N} \mathrm{HCl}, 0.626 \mathrm{~g} 0.16 \mathrm{~N}$ $\mathrm{H}_{2} \mathrm{SO}_{4}$, and $10 \mathrm{ml}$ of a $1000 \mu \mathrm{g} \mathrm{Si} / \mathrm{ml}$ aqueous silica standard (sodium silicate in water). The solutions were allowed to mix using a magnetic stirrer with Teflon coated stir bar until the salts dissolved, and the resultant solution was filtered under vacuum through a $0.2 \mu \mathrm{m}$ Millipore membrane filter to remove precipitated calcite. A $\mathrm{pH}-$ buffered aliquot of this aqueous medium was then prepared by adding 3.9066 $\mathrm{g}$ of the weak acid 2-(4-morpholino) ethane sulfonic acid (MES) to $200 \mathrm{~mL}$ of the filtered synthetic medium and adjusting the $\mathrm{pH}$ to $6\left(\mathrm{pK}_{\mathrm{a}, \mathrm{MES}} \sim 6.1\right.$ at $\left.25^{\circ} \mathrm{C}\right)$ through addition of $1 \mathrm{M} \mathrm{NaOH}$ (typically $8 \mathrm{~mL}$ ). The temperature of the synthetic medium was equilibrated in a closed vessel at the desired reaction temperature prior to the addition of ferrous iron $\left(7.5^{\circ} \mathrm{C}\right.$ in refrigerator, $22^{\circ} \mathrm{C}$ (ambiente), and $50^{\circ} \mathrm{C} / 75^{\circ} \mathrm{C}$ in water bath). Ferrihydrite precipitation was initiated in the presence of $\mathrm{Si}(356 \mu \mathrm{mol} \mathrm{Si} / \mathrm{L})$ and the other matrix components through direct addition of solid ferrous chloride salt $\left(0.0351 \mathrm{~g}\right.$ of $\mathrm{FeCl}_{2} 4 \mathrm{H}_{2} \mathrm{O} ; 1165 \mu \mathrm{mol}$ $\mathrm{Fe} / \mathrm{L}$ ) and mixing was achieved using an overhead paddle stirrer $(\sim 500 \mathrm{rpm})$. Thus the synthesis experiments were conducted with a starting Si:Fe ratio in solution of 0.31 . Evaporation was insignificant at elevated temperatures due to the short synthesis time. After approximately $5 \mathrm{~min}$, a $1 \mathrm{~mL}$ sample of the experimental solution was collected, filtered $(0.2 \mu \mathrm{m}$ nylon syringe filter) and the concentration of dissolved $\mathrm{Fe}^{2+}$ was measured colorimetrically using 
1,10-phenanthroline at $510 \mathrm{~nm}$ on a Hach DR/2010 spectrophotometer. Ferrous iron measurements were repeated at regular intervals until at least $50 \%$ of the ferrous iron (introduced as ferrous chloride) had been oxidized. At the end of the oxidation-precipitation experiment, the iron oxide solids were collected by vacuum filtration on a $0.2 \mu \mathrm{m}$ polycarbonate membrane filter. The filtered solids were immediately washed with deionized water and then allowed to air-dry. The dried solids were scraped from the filter surface and stored for further characterization. Multiple syntheses were conducted at each reaction temperature to ensure reproducibility, which was confirmed through calculation of $\mathrm{Fe}^{2+}$ oxidation rate along with mineralogical characterization.

[10] For simplicity, Si-Fh samples are denoted as Fh7.5, Fh22, Fh50, and Fh75, with each number serving as a reference for each synthesis temperature $\left(7.5^{\circ} \mathrm{C}, 22^{\circ} \mathrm{C}\right.$, $50^{\circ} \mathrm{C}$, and $75^{\circ} \mathrm{C}$, respectively).

\subsection{Natural Ferrihydrite}

[11] The natural ferrihydrite sample, $B C-11$, was collected in the spring of 2003 at a marine shallow-water hydrothermal system in Bahia Concepcion, Baja California, Mexico. The shallow-water hydrothermal system consists of several small vents approximately 30 to $50 \mathrm{~m}$ offshore at a depth of 7 to $10 \mathrm{~m}$. The hydrothermal fluid $\mathrm{pH}$ and temperature were measured at three different vents and ranged from 5.9 to 6.1 and 87 to $89^{\circ} \mathrm{C}$, respectively. The vent fluid salinity and chemical composition were similar to those of seawater, with the exception of $\mathrm{Si}, \mathrm{Fe}$, and As. These three elements were enriched relative to seawater by up to 500 times, a common phenomenon in marine shallow-water hydrothermal systems [e.g., Pichler et al., 1999a].

[12] Sample BC-11 is part of the hydrous ferric oxide (HFO) deposits that formed around the vent sites. Those deposits were present throughout the area of hydrothermal activity where they formed as very thin layers on sediment grains in areas of high seafloor temperature. Massive layers and extensive filling of sediment pore space, however, were restricted to the vicinity of vent sites. Deposits varied in color from a bright orange to very dark brown that is almost black, and in Moh's hardness from $<1$ to about 2.5, similar to the marine shallow-water hydrothermal system in Tutum Bay, Papua New Guinea [Pichler et al., 1999b]. Chemically, $B C$-11 also compares well to ferrihydrite deposits in Tutum Bay with $\mathrm{Fe}(\sim 40 \mathrm{wt} \%), \mathrm{Si}(\sim 10 \mathrm{wt} \%)$, and As ( $\sim 5 \mathrm{wt} \%)$ being the most abundant elements.

\section{Experimental Details}

[13] A commercial SQUID magnetometer (MPMS-XL; Quantum Design) was employed to perform static (ZFC/FC susceptibility curves, hysteresis loops) and dynamic (ac susceptibility curves) measurements as a function of field, temperature and driving frequency. Zero-field-cooled (ZFC) magnetization curves were obtained by cooling in zero field from a high temperature $(300 \mathrm{~K})$ to a low temperature $(2 \mathrm{~K})$ and then measuring the magnetization at stepwise increasing temperatures from $2 \mathrm{~K}$ to $300 \mathrm{~K}$ in a small applied field $(\mathrm{B}=5 \mathrm{mT})$. The sample was again cooled, in the same field, and field cooled (FC) magnetization curves were obtained by measuring at stepwise increasing temperatures, from $2 \mathrm{~K}$

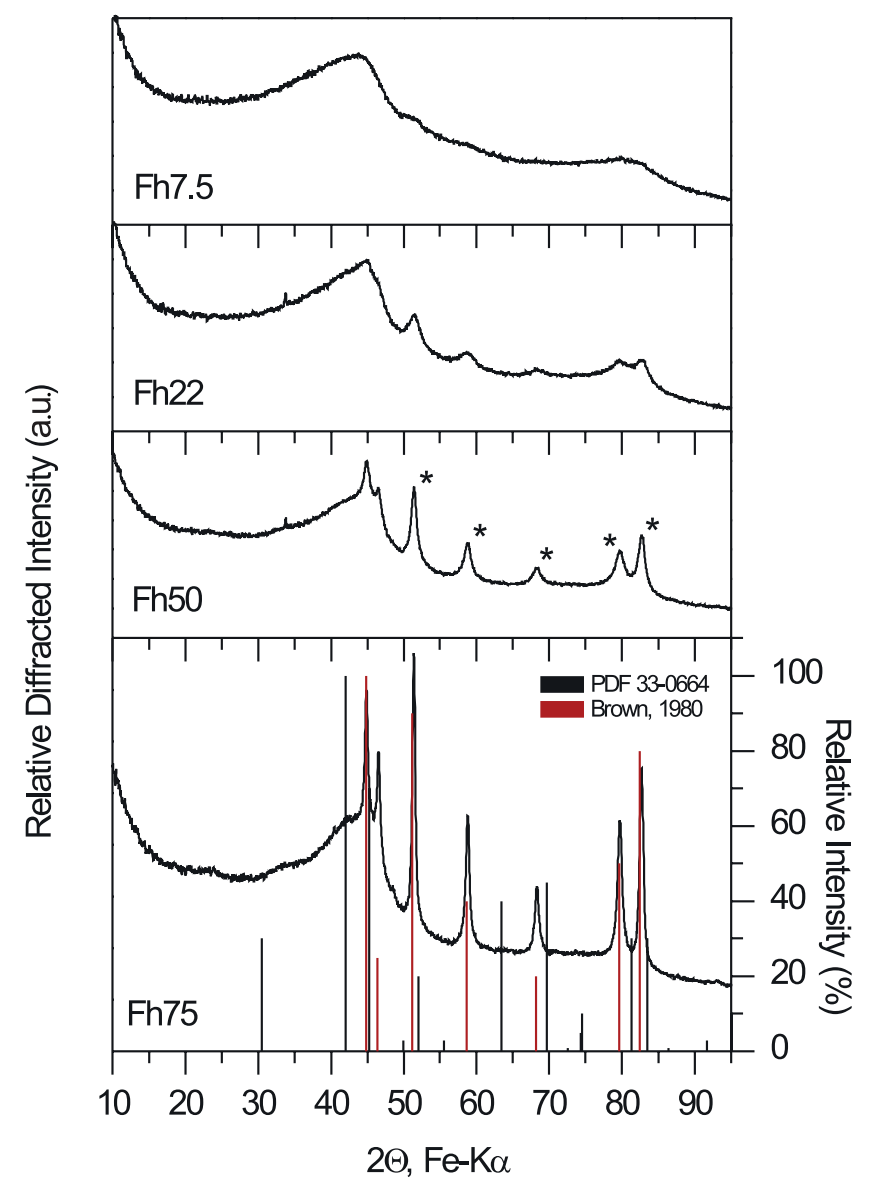

Figure 1a. XRD for all four samples showing the sevenline patterns reflecting particle size increase for samples prepared at different temperatures. Relative peak intensities for hematite (PDF 33-0664) and crystalline ferrihydrite [Brown, 1980] are included for reference. The stars indicate peaks used to calculate crystallite dimensions based on the Scherrer formula; only four peaks could be fit for sample Fh7.5.

to $300 \mathrm{~K}$. Hysteresis loops were obtained by using maximum applied fields up to $5 \mathrm{~T}$ at temperatures of 2, 100, 200, and $300 \mathrm{~K}$. The ac susceptibility $\left(\chi^{\prime}\right)$ curves were measured in the temperature range $2-400 \mathrm{~K}$. Mössbauer spectra were measured at room temperature and at $4.2 \mathrm{~K}$. A conventional constant-acceleration spectrometer was used in transmission geometry with a ${ }^{57} \mathrm{Co} / \mathrm{Rh}$ source, using $\alpha$-Fe at room temperature to calibrate isomer shifts and velocity scale.

[14] Dried sample powders were characterized by X-ray diffraction using a Rigaku Miniflex diffractometer. Dried solids $(10-15 \mathrm{mg})$ were transferred to a zero-background quartz slide. The solids were then saturated with methanol, spread evenly on the surface of the slide, and then allowed to air-dry. Diffraction data were collected using $\mathrm{Fe} \mathrm{K} \alpha$ radiation $(30 \mathrm{kV}, 15 \mathrm{~mA})$ over an angular range of $5-95^{\circ} 2 \Theta$ with a $0.02^{\circ}$ step size $(12 \mathrm{~s} / \mathrm{step})$. Goniometer alignment was checked externally using NIST SRM640b (silicon) prepared in the same manner.

[15] Samples for high-resolution transmission electron microscopy (HRTEM) were prepared by two methods. First, 


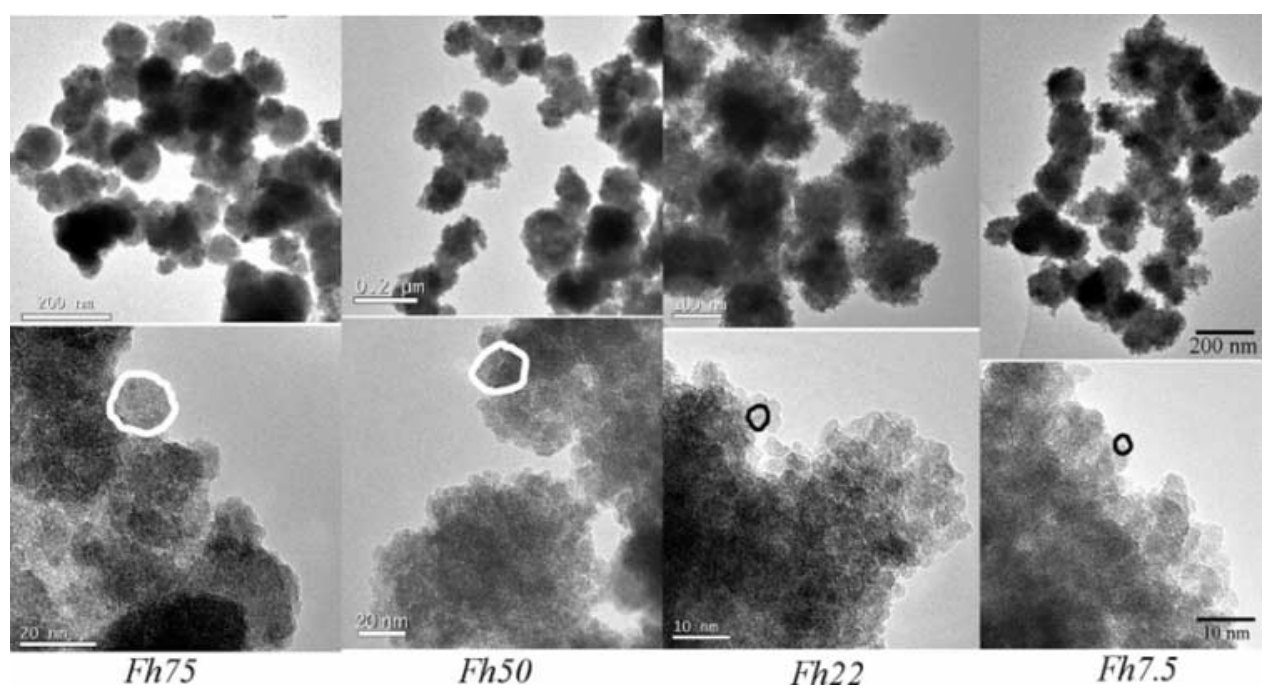

Figure 1b. HRTEM images show the samples are constituted of aggregated (upper pictures) particles and there is a trend of decrease in the primary particle size (circles) with decrease of synthesis temperature.

the dried samples were simply resuspended in purified water, vortexed for a few minutes, and sonicated for a few minutes. While the powders did seem to resuspend readily, a second preparation method was adopted in order to attempt to compare the aggregation state of the particles before and after the drying step. The second method involved syringe filtering the ferrihydrite suspension through a $0.2 \mu \mathrm{m}$ Nuclepore polycarbonate track etch filter membrane. The supernatant was clear and colorless. Filtration was followed by passing purified water through the filter in order to remove dissolved side-products, salts, and buffers from the particles, and the liquid passed through the filter was again clear and colorless. The filter assembly was disassembled, and the filter was placed in $1 \mathrm{~mL}$ of purified water and sonicated for several minutes and vortexed for several minutes. The particles were readily resuspended. A small amount of the suspension resulting from each method was diluted and a single drop placed onto a 200 mesh holey carbon-coated copper grid (SPI), which was then allowed to dry in air. TEM images were collected using either an FEI Tecnai T12 TEM operated at $120 \mathrm{kV}$ or an FEI Tecnai G2 30 operated at $300 \mathrm{kV}$. All images were collected using a charge-couple device (CCD) camera, and high-resolution images were collected using the lowest intensity conditions possible.

\section{X-Ray Diffraction and TEM}

[16] Figure 1a shows the XRD patterns obtained for synthetic samples precipitated in the presence of silica. The X-ray diffraction (XRD) patterns for Si-bearing samples synthesized at $7.5^{\circ} \mathrm{C}$ and $22^{\circ} \mathrm{C}$ are represented by the usual broad lines characteristic for ferrihydrite found in soils and natural environments [e.g., Carlson and Schwertmann, 1981; Schwertmann et al., 1982]. For the other two samples prepared at $50^{\circ} \mathrm{C}$ and $75^{\circ} \mathrm{C}$, unusual diffraction patterns with seven, comparatively sharp lines were obtained. The XRD pattern for the $B C-11$ ferrihydrite sample also showed seven lines (Figure 2a) and the sharp lines suggest the presence of a well-crystallized material. These patterns are similar to that presented by Childs [1992], which exhibited seven sharp lines. Comparison of our diffraction data for samples Fh75 and BC-11 to peaks identified by Brown [1980] reveals consistency both in peak location and relative intensity. Results shown in Figure 1a and documented in Table 1 demonstrate that diffraction peaks identified in our sample patterns can be attributed solely to ferrihydrite. The sharp peak identified at $\sim 2.54 \AA$ could potentially be associated with goethite (2.45 $\AA$ indexed as (111) in PDF 290713), but no other peak is present within the pattern to confirm the presence of this phase (e.g., $4.183 \AA$ indexed as (110) in PDF 29-0713). It should be noted that the peak at $\sim 2.54 \AA$ has been indexed within recently proposed structural models for ferrihydrite [Drits et al., 1993; Janney et $a l ., 2001]$. In addition, review of published diffraction data for synthetic and natural "6-line" ferrihydrites consistently reveal the presence of a shoulder on the high two-theta side

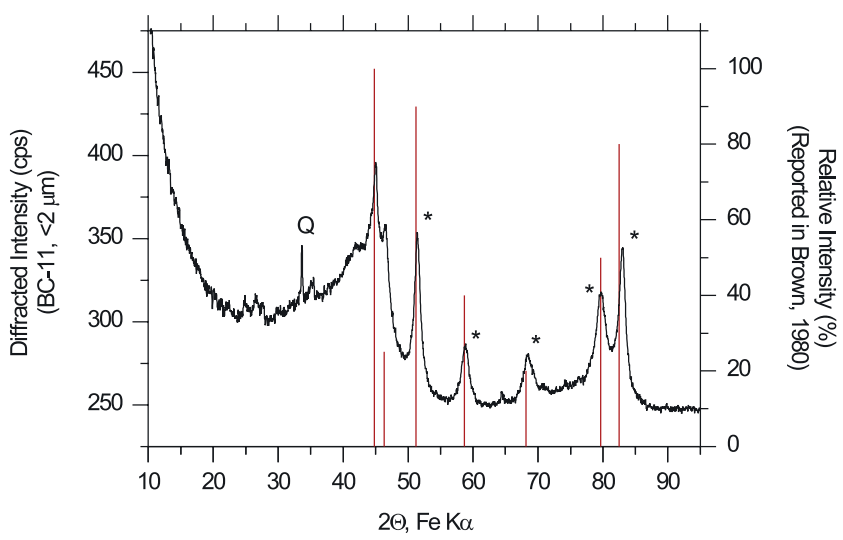

Figure 2a. Characterization of a natural "7-line" ferrihydrite collected from a marine shallow-water hydrothermal area near Bahia Concepcion. The stars indicate peaks used to calculate crystallite dimensions based on the Scherrer formula; Q refers to quartz. 

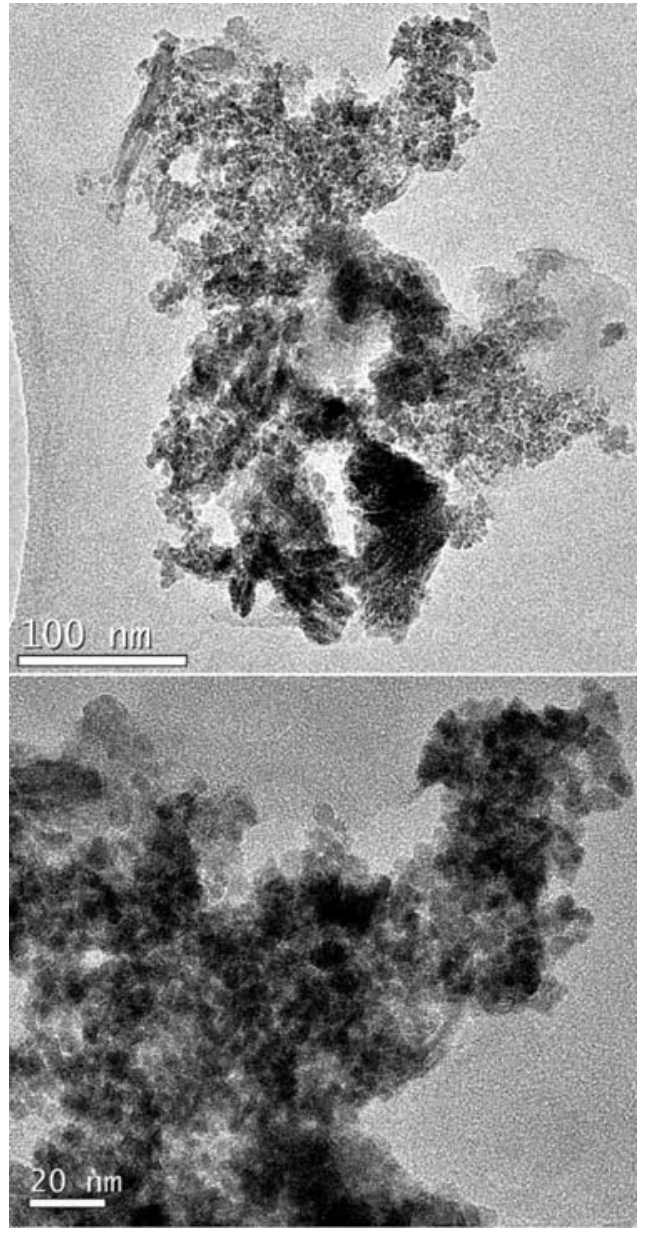

Figure 2b. HRTEM images for natural ferrihydrite (sample $B C$-11).

of the main ferrihydrite peak located at $\sim 2.45 \AA$. Our diffraction data confirm that ferrihydrite is the only detectable phase within our synthetic samples. In samples Fh50 and $F h 75$, there is also a notable broad reflection located in the region of $40-50$ degrees two-theta ( $\mathrm{Fe} \mathrm{K} \alpha$ radiation). This peak is similar to that observed in the diffraction pattern for the poorly crystalline ferrihydrite (sample Fh7.5). It thus appears that samples $F h 50$ and $F h 75$ consist of a heterogeneous mixture of material consistent with larger and more crystalline seven-line ferrihydrite and a less crystalline material with much smaller particle size. This is consistent with the notion of ferrihydrite particle growth proposed by Parfitt et al. [1992] in the presence of silica, i.e., our samples Fh50 and Fh75 represent mixtures of ferrihydrite particles of varying size similar to the schematic models presented by these authors (their Figure 4). As discussed below, the magnetics data collected for these samples supports this observation.

[17] In general, HRTEM characterization shows the synthetic and natural ferrihydrite particles are heavily agglomerated (Figures $1 \mathrm{~b}$ and $2 \mathrm{~b}$ ). While it is difficult to generate a particle size analysis from these images, a general trend of increasing primary particle size (a few to several $\mathrm{nm}$ in diameter and represented by circles in Figure 1b) with increasing temperature is evident while the size of the agglomerates seems independent of temperature. Lattice fringes in the HRTEM images confirm that these materials are crystalline and confirm that the single crystal size increases with increasing temperature. Interestingly, single crystal domains appear to be composed of an increasing number of primary particles with increasing oxidation temperature, as evidenced by features like dimples and the incorporation of defects. This could be the result of an increase in oriented aggregation or solid state recrystallization at the higher temperatures. As features like dimples, pores, and slight misorientation between crystalline primary particles are retained, the former is probably more likely [Penn, 2004]. HRTEM characterization for sample $B C-11$ (Figure $2 b$ ) shows the particles are not well dispersed.

\section{Magnetic Study}

\subsection{ZFC/FC Susceptibility and Hysteresis Loops}

[18] Figure 3 shows ZFC/FC susceptibility curves from all four synthetic samples, and three of the four samples exhibit typical superparamagnetic behavior (e.g., as discussed by

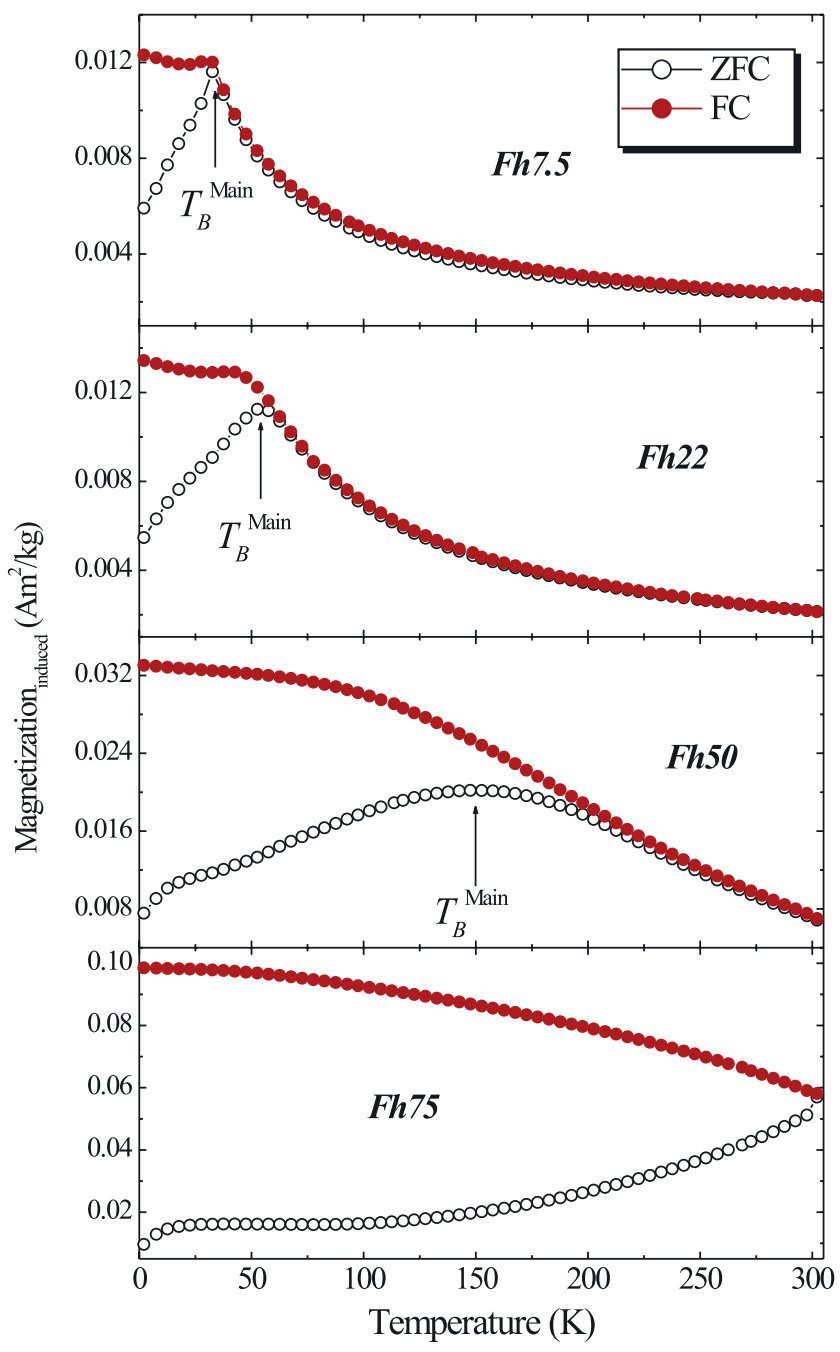

Figure 3. $\mathrm{ZFC} / \mathrm{FC}$ curves with applied field of $5 \mathrm{mT}$ showing the decrease of $T_{B}{ }^{\text {Main }}$ with the synthesis temperature. Note that $T_{B}{ }^{\text {Main }}$ for $F h 75$ is clearly greater than $300 \mathrm{~K}$. 
Table 1. Reported d-Spacings $(\AA)$ for Peaks Identified in Powder Diffraction Patterns for Ferrihydrite and Other Iron Oxides With Related Structures

\begin{tabular}{|c|c|c|c|c|c|c|c|c|c|}
\hline \multicolumn{6}{|c|}{ Ferrihydrite Samples } & \multicolumn{4}{|c|}{ ICDD Powder Diffraction File } \\
\hline $\begin{array}{l}F h 75 \\
(\mathrm{Fe} \mathrm{K} \alpha)^{\mathrm{a}}\end{array}$ & $\begin{array}{c}B C-11 \\
(\mathrm{Fe} \mathrm{K} \alpha)^{\mathrm{a}}\end{array}$ & $\begin{array}{c}\text { Childs [1992] } \\
(\mathrm{Co} \mathrm{K} \alpha) \\
(\mathrm{FH} 9037)^{\mathrm{b}}\end{array}$ & $\begin{array}{l}\text { Brown } \\
{[1980]}\end{array}$ & $\begin{array}{c}\text { Stanjek and } \\
\text { Weidler }[1992] \\
(\mathrm{Co} \mathrm{K} \alpha)\end{array}$ & $\begin{array}{c}\text { Janney et al. } \\
{[2000](\mathrm{Cr} \mathrm{K} \alpha)}\end{array}$ & $\begin{array}{l}\text { Ferrihydrite } \\
\text { PDF 29-712 }\end{array}$ & $\begin{array}{l}\text { Feroxyhyte }{ }^{c} \\
\text { PDF 13-0087 }\end{array}$ & Schwertmannite $^{\mathrm{d}}$ & $\begin{array}{c}\text { Hematite } \\
\text { PDF 33-0664 } \\
\end{array}$ \\
\hline$(4.76)$ & - & 4.6 & - & 4.55 & 4.56 & - & 4.61 & 4.86 & - \\
\hline$(3.40)$ & - & 3.4 & - & 3.32 & 3.21 & - & - & 3.39 & 3.684 \\
\hline- & - & - & - & $2.717^{\mathrm{e}}$ & - & - & - & - & 2.7 \\
\hline 2.541 & 2.523 & 2.54 & 2.54 & 2.517 & $2.52^{\mathrm{f}}$ & 2.50 & 2.545 & 2.55 & 2.519 \\
\hline 2.454 & 2.446 & 2.46 & 2.46 & - & $\begin{array}{c}{[\text { Janney et al. }} \\
2001]^{\mathrm{g}}\end{array}$ & - & - & - & - \\
\hline 2.236 & 2.231 & 2.28 & 2.24 & 2.239 & 2.22 & 2.21 & 2.255 & 2.28 & 2.292 \\
\hline - & - & - & - & - & - & - & - & - & 2.207 \\
\hline 1.974 & 1.966 & $\begin{array}{c}1.98 \\
-\end{array}$ & $\begin{array}{c}1.977 \\
-\end{array}$ & $\begin{array}{c}1.977 \\
-\end{array}$ & $\begin{array}{c}1.96 \\
-\end{array}$ & $\begin{array}{c}1.96 \\
-\end{array}$ & - & $\begin{array}{c}1.95 \\
-\end{array}$ & $\begin{array}{c}2.077 \\
1.84\end{array}$ \\
\hline 1.726 & 1.721 & 1.73 & 1.727 & 1.699 & 1.70 & 1.72 & 1.685 & 1.66 & 1.694 \\
\hline - & - & - & - & - & - & - & - & - & 1.636 \\
\hline- & - & - & - & - & - & - & - & - & 1.603 \\
\hline 1.511 & 1.509 & 1.51 & 1.512 & 1.5048 & 1.49 & 1.51 & - & 1.51 & 1.599 \\
\hline 1.466 & 1.460 & 1.47 & 1.469 & 1.4714 & 1.47 & 1.48 & 1.471 & 1.46 & 1.485 \\
\hline
\end{tabular}

anternal position standard employed: (1) Fh75, NIST SRM640b, d-spacings in parentheses are tentative due to presence as broad reflections with low intensity; (2) BC-11, halite (NaCl) PDF 05-0628.

${ }^{\mathrm{b}}$ Prepared by hydrolysis of $\mathrm{FeSO}_{4}\left(0.1 \mathrm{~mol} \mathrm{~L}^{-1}\right)$ and $\mathrm{Na}_{2} \mathrm{SiO}_{3}$ (ca. $\left.0.015 \mathrm{~mol} \mathrm{~L}^{-1}\right)$ at $\mathrm{pH} 7$ and room temperature.

${ }^{c}$ Reflections are also reported at $1.271 \AA, 1.223 \AA$, and $1.104 \AA$; d-spacings at 4.61 and $1.104 \AA$ are not indexed in PDF 13-0087. Also see Drits et al. [1993].

dJambor et al. [1995].

${ }^{\text {e}}$ Peak identified through profile fitting; not clearly evident as separate peak in pattern.

${ }^{\mathrm{f}}$ Note that there is evidence of a shoulder on the high-angle side of the peak identified at $2.52 \AA$ by Janney et al. [2000, Figure 1].

${ }^{\mathrm{g}}$ Janney et al. [2001] present a simulated diffraction pattern (their Figure 7) for 6-line ferrihydrite using a double-hexagonal structure with a reflection indexed as (101) that corresponds to the location of the peak observed at $\sim 2.45 \AA$ for samples Fh75 and BC-11; also indexed as (101) by Drits et al. [1993].

Dormann et al. [1997]). When the magnetizations of individual superparamagnetic particles are "frozen" by cooling without an applied field, the magnetic moments are randomly oriented and the resulting induced magnetization is zero at $0 \mathrm{~K}$. With increasing temperature and in the presence of an applied field, the magnetic moments begin to fluctuate and then align in the direction of the field, leading to an increase of the total magnetization [Chantrell et al., 1991; Dormann et al., 1997]. Above the blocking temperature $\left(T_{B}\right)$, the temperature associated with the peak observed in the ZFC curves, the thermal energy of disorder is higher than the ordering energy associated with the applied field and anisotropy energy barrier $\left(K_{\text {eff }} V\right)$, and a superparamagnetic behavior results, leading to a decrease of the total magnetization with increasing temperature following the Curie-Weiss law. The presence of a maximum in the ZFC susceptibility curve is therefore associated with the transition between magnet- ically relaxing superparamagnetic (unblocked) and thermally stable magnetization (blocked state; at this point we are not discussing Néel temperature) [Hansen and Mørup, 1999]. Each particle is associated with a given volume and corresponding value of $T_{B}$. A wide or narrow distribution of particle volumes will produce a $T_{B}$ distribution and will also result in a broad or narrow peak for the ZFC curve. As can be seen in Table 2 and Figure 3, the blocking temperature $\left(T_{B}^{\text {Main }}\right)$ drops substantially with decreasing synthesis temperature, from above $300 \mathrm{~K}$ for sample $F h 75$ to about $33 \mathrm{~K}$ for sample $F h 7.5$. For samples $F h 75$ and $F h 50$ there seems to be present an additional distribution of fine particles $\left(T_{B}^{\text {Fine }}\right)$ with variable $T_{B}$ s around $25 \mathrm{~K}$. This population of extremely small particles is represented by a small shoulder on the ZFC curve; out of phase ac susceptibility in Figure 5 inset (see below) also present evidences of presence of these small particles with similar $T_{B}^{\text {Fine }}$. The ZFC/FC curves of dc

Table 2. Hysteresis Parameters Estimate at $2 \mathrm{~K}, T_{B}$ Determined at ZFC Curves and Particle Diameter Calculated by XRD ( $\left.d_{X R D}\right)$ and by Using Blocking Temperature $\left(\mathrm{d}_{\mathrm{TB}}\right)^{\mathrm{a}}$

\begin{tabular}{|c|c|c|c|c|c|c|c|}
\hline $\begin{array}{c}\text { Sample } \\
\text { (Number of Replicates) } \\
\end{array}$ & $\begin{array}{l}\text { Synthesis Temp., } \\
{ }^{\circ} \mathrm{C} \text { (Time, hours) }\end{array}$ & $\begin{array}{c}\text { Composition Fe, } \\
\mathrm{wt} \%(\mathrm{Si}, \mathrm{wt} \%)\end{array}$ & $\mathrm{M}_{\mathrm{S}}, \mathrm{Am}^{2} / \mathrm{kg}$ & $\mathrm{H}_{\mathrm{C}}, \mathrm{T}$ & $\mathrm{T}_{\mathrm{B}}, \mathrm{K}$ & $\mathrm{d}_{\mathrm{TB}}, \mathrm{nm}$ & $\mathrm{d}_{\mathrm{XRD}}, \mathrm{nm}$ \\
\hline Fh7.5 (2) & $7.5(56.2)$ & $51.7(3.5)^{\mathrm{b}}$ & 5.6 & 0.36 & 33 & 5.1 & $1.9(0.7)$ \\
\hline Fh22 (5) & $22(2.8-25.6)$ & $57.6(1.9)$ & 5.3 & 0.34 & 50 & 5.9 & $5.4(1.5)$ \\
\hline Fh50 (5) & $50(0.53-1.95)$ & $64.4(1.3)$ & 7.0 & 0.31 & 150 & 8.5 & $10.4(1.6)$ \\
\hline Fh75 (5) & $75(0.15-0.47)$ & $66.5(1.7)$ & 7.2 & 0.27 & 330 & 11.1 & $23.6(3.0)$ \\
\hline BC-11 & $87-89^{\mathrm{c}}$ & $\sim 40(\sim 10)$ & 7.9 & 0.10 & $33,>400$ & $5.1,>11.8$ & $9.1(2.0)$ \\
\hline
\end{tabular}

${ }^{\mathrm{a}}$ One standard deviation is shown in parentheses for the mean $d_{(X R D)}$ calculated using four or five diffraction peaks and the Scherrer relationship. Except for synthesis temperature, reported data are for composited samples.

${ }^{\mathrm{b}}$ Estimated $4.4 \mathrm{wt} \% \mathrm{Si}$ based on differences in dissolved $\mathrm{Fe}$ and $\mathrm{Si}$ at the beginning and end of the experiments relative to an assumed formula for ferrihydrite $\left(\mathrm{Fe}_{5} \mathrm{HO}_{8} \cdot 4 \mathrm{H}_{2} \mathrm{O}, 480 \mathrm{~g} / \mathrm{mole}\right)$.

${ }^{c}$ Rate of ferrous iron oxidation and apparent time of ferrihydrite formation is unknown for this sample. 

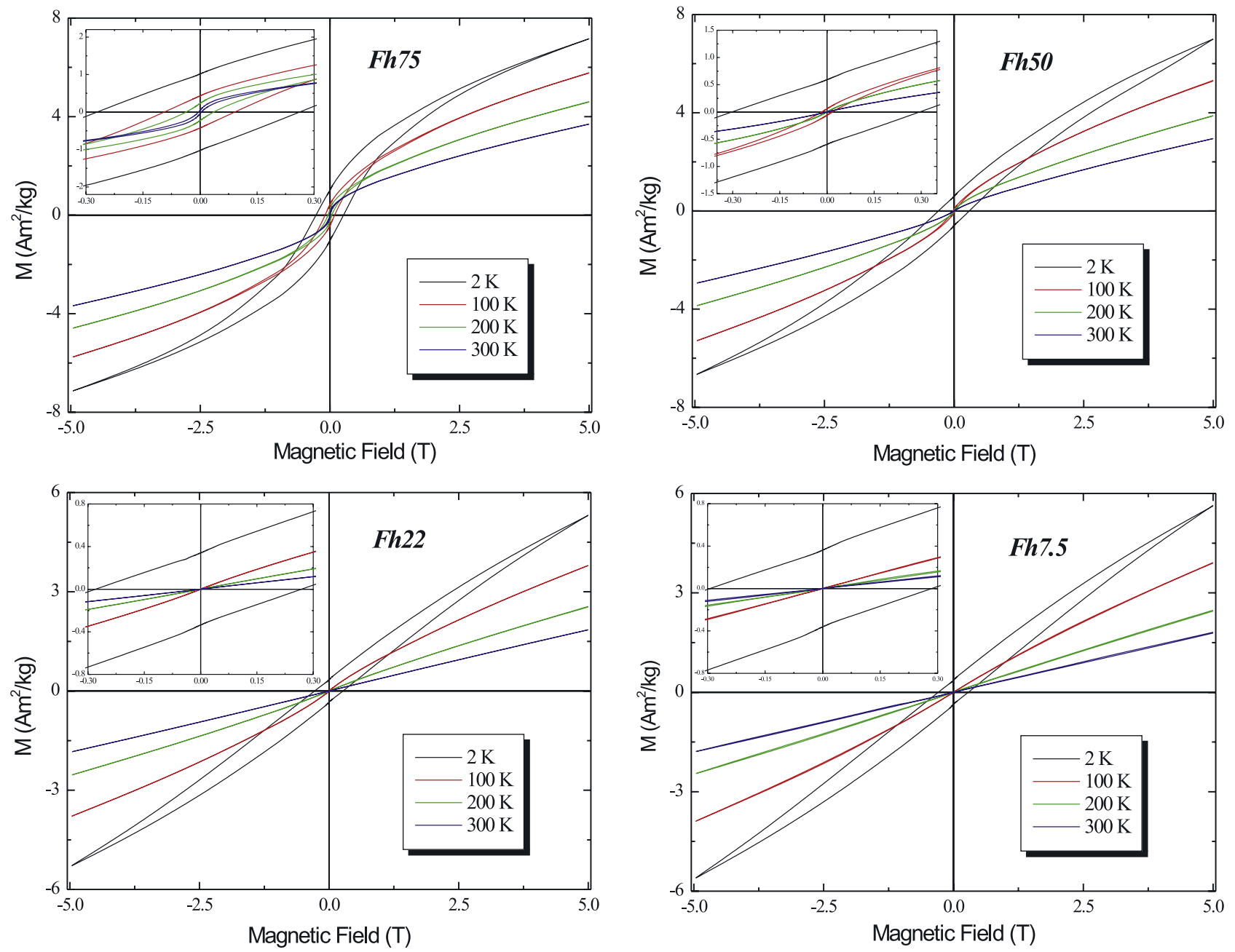

Figure 4. Hysteresis loops for Fh75, Fh50, Fh22, and Fh7.5. Data were collected at 2, 100, 200, and $300 \mathrm{~K}$. Hysteresis loops did not attain saturation at $5 \mathrm{~T}$.

susceptibility together with ac susceptibility information (see below) help us to fully infer the particle size distribution and its width.

[19] With the mean blocking temperature obtained from $\mathrm{ZFC}$ curve, it is possible to estimate the mean volume $(V)$ of the particles through the relation:

$$
V=\frac{25 k_{B} T_{B}}{K}
$$

where $k_{B}$ is Boltzmann constant, $K$ is the anisotropy constant, and $T_{B}$ is the mean blocking temperature [Cullity, 1972; Chantrell et al., 1991]. By considering a spherical particle shape it is possible to obtain an estimate of the mean particle diameter. The expression above is very useful to estimate grain size from materials when the anisotropy constant is well determined. However, in the case of ferrihydrite, there is very little information on anisotropy constants in the literature. We have, however, used the magnetocrystalline anisotropy constant determined for typical particle size of ferrihydrite $(\sim 5 \mathrm{~nm})$ of $1.7 \times 10^{5} \mathrm{~J} / \mathrm{m}^{3}$ [Rodmacq, 1984]. Thus we could estimate the magnetic particle sizes for all four samples (see Table 2). The diameters estimated by using the anisotropy constant above present a trend of increase with synthesis temperature like that observed by XRD. For the larger sample Fh75 the value obtained $(11.1 \mathrm{~nm})$ is quite different from the one estimated by XRD $(23 \mathrm{~nm})$. The particle size disagreement observed in large particles could be associated with an incorrect value for the anisotropy constant used in our calculations. The anisotropy constant used in our estimate for all samples was the one obtained from typical ferrihydrite particle size (around $5 \mathrm{~nm}$ ) where finite size effects, like surface anisotropy and dipolar interactions are important contributions, are taken into account. Since XRD data shows that this ferrihydrite sample $(F h 75)$ clearly contains much larger grains (above $10 \mathrm{~nm}$ ) the anisotropy constant used could be an overestimate, since the contributions from finite size are not so important for these larger particles. For sample Fh7.5 effects due to interactions and/or the core/shell relationship could be related to the overestimate of particle size. Particles size estimates for samples Fh22 and Fh50 are in agreement considering the experimental error.

[20] The hysteresis loops at $2 \mathrm{~K}$ of all four synthetic samples are presented in Figure 4. Each sample displays a lack of saturation even at a magnetic field of $5 \mathrm{~T}$. Another 


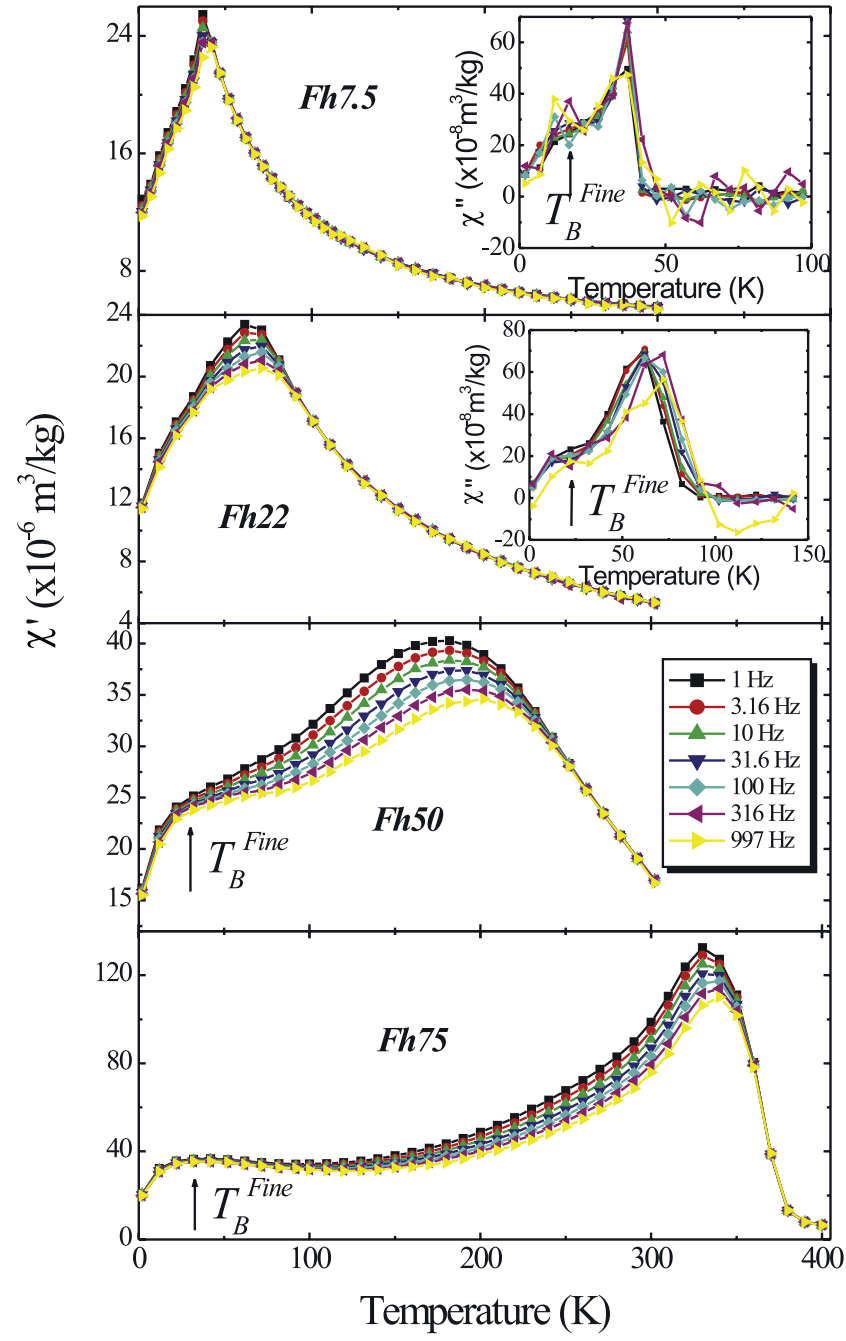

Figure 5. The ac susceptibility data for all for samples showing the peak temperature at different frequencies and the distribution of particles size with synthesis temperature. $T_{B}^{\text {Fine }}$ represents the blocking temperature for the small size fraction.

interesting feature observed relates to coercive force $\left(H_{C}\right)$ and remanent magnetization $\left(M_{R}\right)$. The $H_{C}$ values are similar but still show a trend of increase with increasing synthesis temperature, while the $M_{R}$ values decrease with decreasing synthesis temperature (or decreasing particle size), although a small deviation from this trend is observed for sample Fh22. These two parameters are sensitive to grain size and composition variations and the $M_{R}$ decrease with particle size could be related to Si-content. In our case, the variation of grain size is conspicuous, but we can not discard possible structural effects due to the incorporation of Si. The hysteresis loops obtained at $100 \mathrm{~K}, 200 \mathrm{~K}$, and $300 \mathrm{~K}$ for samples $F h 22$ and $F h 7.5$ are represented mainly by a straight line with a small sigmoidal behavior, such as is expected from a superparamagnetic component; a similar behavior was found by Zergenyi et al. [1999] and Guyodo et al. [2006]. For the other two samples, Fh75 and Fh50, a sigmoidal $M$ versus $B$ pattern was observed, and even an open hysteresis loop was obtained for sample $F h 75$ at $300 \mathrm{~K}$.
These behaviors are in agreement with ZFC/FC curves, since above $T_{B}$ we expect a pure superparamagnetic behavior very much like a paramagnetic material.

\subsection{The ac Susceptibility}

[21] Figure 5 displays the ac susceptibility $\chi(T, f)$ data for the four Si-ferrihydrite synthetic samples. Both real $\chi^{\prime}(T)$ and imaginary $\chi^{\prime \prime}(T)$ components exhibit the expected behavior of a superparamagnetic system, that is to say, the occurrence of a maximum at a temperature $T_{m}$. At temperatures above $T_{m}, \chi^{\prime}$ is frequency independent indicating thermodynamic equilibrium, as expected in a temperature range where all the particles are in a superparamagnetic state. However, at $T \leq T_{m}, \chi^{\prime}$ is frequency-dependent, indicating a nonequilibrium situation, as expected when a fraction of particles are in the blocked state [Dormann et al., 1997]. Since $T_{m}$ depends on the measurement frequency, the peak occurs at different temperatures for different frequencies. The general behavior observed is the shift of this maximum toward higher temperatures with increase of the driving frequency. This information further supports the ZFC dc susceptibility data where we also observed the increase of blocking temperature (which represents the particle volume) as a consequence of the increase of synthesis temperature.

[22] The real component $\left(\chi^{\prime}\right)$ presents an additional peak around $25 \mathrm{~K}$ (related to very small particles) for samples Fh75 and Fh50 such as what was observed for the ZFC curves. From the imaginary component $\left(\chi^{\prime \prime}\right)$ we also could observe the contribution related to those small particles with $T_{m} \sim 25 \mathrm{~K}$ for samples Fh22 and Fh7.5 (Figure 5 inset).

\subsection{Mössbauer Spectroscopy}

[23] Figure 6 shows the Mössbauer spectra at room temperature and $4.2 \mathrm{~K}$ for samples $F h 75$ (largest) and Fh7.5 (smallest). At $4.2 \mathrm{~K}$ the spectra for all four samples are only sextets, indicating a complete magnetic order. The hyperfine parameters, magnetic hyperfine field $\left(B_{H F}\right)$, quadrupole splitting $(Q S)$, and isomer shift $(I S)$, are presented in Table 3 and are in agreement with literature values of ferrihydrite [Murad and Cashion, 2004], although a small decrease of $B_{H F}$ is seen when compared with a pure, "well" crystallized ferrihydrite. This decrease of $B_{H F}$ could be associated with silicon substitution since it has been known that isomorphic substitution (doping) reduces the magnetic hyperfine field. On the other hand, we also know that lattice vacancies can produce a similar effect of decrease in $B_{H F}$. Schwertmann et al. [2004] reported a similar $B_{H F}$ decrease due to incorporated Si. Sample Fh7.5 has the maximum deviation when compared with the standard $B_{H F}$ values of ferrihydrite at 4.2 K (50.8 T [Murad and Cashion, 2004]) and the X-ray diffraction patterns match with typical, poorly crystallized pattern of ferrihydrite. It seems there are two concurrent effects of the decrease in synthesis temperature: (1) an increase in the structural substitution of iron by Si and (2) a decrease in the crystallinity of the material (vacancies increase). The Mössbauer spectra at room temperature are represented by doublets for samples Fh50, Fh22, and Fh7.5. The exception is sample $F h 75$, which presents a collapsed magnetic hyperfine field, suggesting relaxation effects. Such an effect is in agreement with the magnetic data, which show an open hysteresis loop at room temperature 

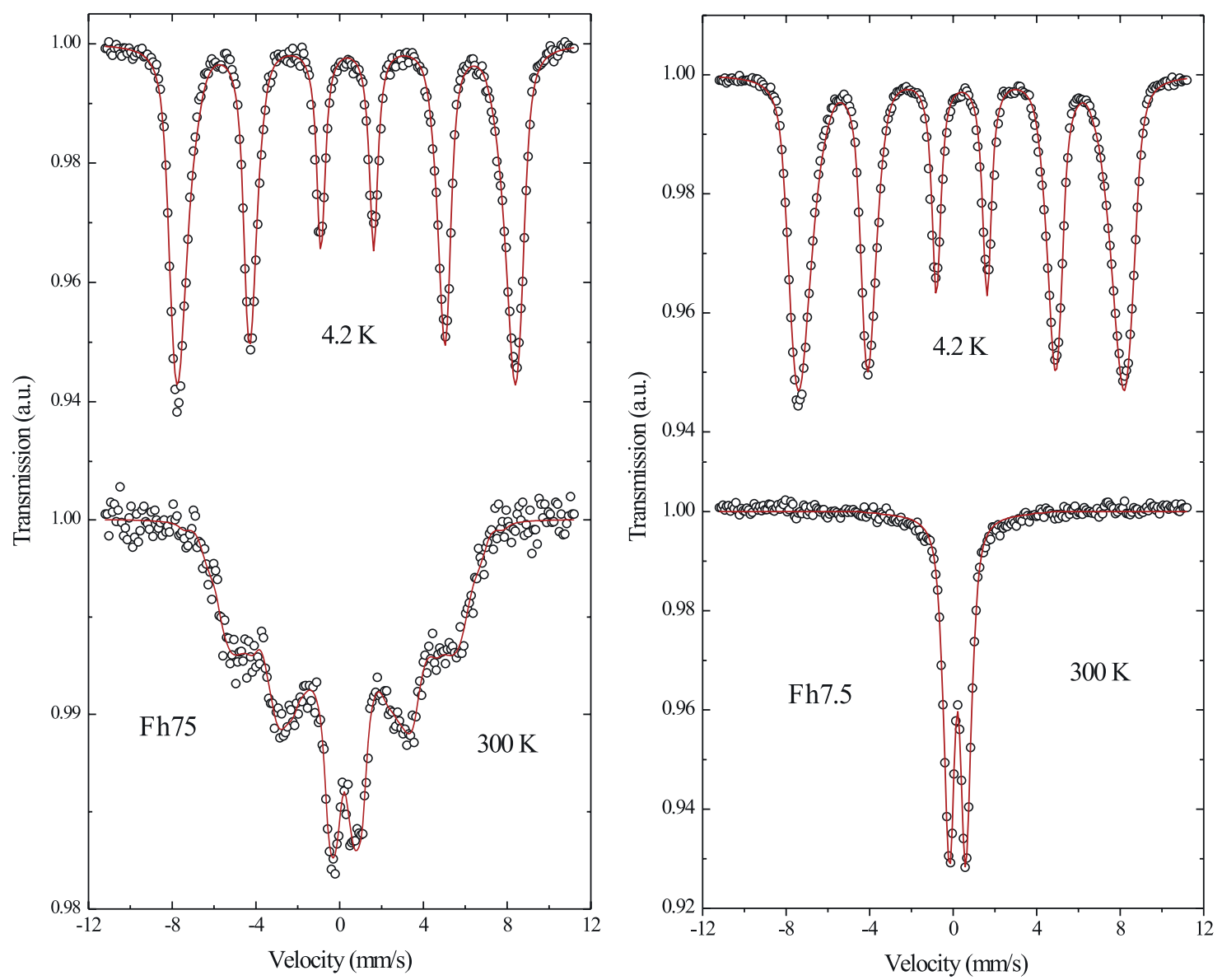

Figure 6. Mössbauer spectra at room temperature and $4.2 \mathrm{~K}$ for samples $F h 75$ and $F h 7.5$. At $4.2 \mathrm{~K}$ the particles are blocked and the sextet corresponding to ferrihydrite was fitted. At room temperature Fh7.5 present the usual superparamagnetic behavior represented by a doublet and Fh75 shows a collapsed magnetic hyperfine field resulting from relaxation effects. Open circles are experimental points and line is the best fitting.

and a $T_{B}^{\text {Main }}$ from ZFC curves and $T_{m}$ from ac susceptibility above $300 \mathrm{~K}$.

\section{Particle Size Analysis of the Natural Ferrihydrite Particles (BC-11): Magnetic Information}

[24] The magnetic information from sample $B C-11$ seems to represent the sum of three distinct magnetic behaviors. The first is related to the presence of superparamagnetic particles represented by the peak around $33 \mathrm{~K}$ in $\mathrm{ZFC}$ curve and in ac susceptibility curves (Figures $7 \mathrm{a}$ and $7 \mathrm{~b}$ ). The second is a paramagnetic contribution, which can be observed in the ZFC and ac susceptibility curves at temperatures below $10 \mathrm{~K}$. Such a contribution is clear from the susceptibility increase at very low temperatures $(2 \mathrm{~K})$ and is confirmed by the fact no out of phase susceptibility component is observed (Figure $7 \mathrm{~b}$ inset). The third is related to the remanent magnetization at room temperature. The frequency dependency in ac susceptibility curves clearly demonstrates a broad particle size

Table 3. Mössbauer Hyperfine Parameters at Room Temperature and $4.2 \mathrm{~K}$ for Synthetic and Natural Ferrihydrite $^{\mathrm{a}}$

\begin{tabular}{|c|c|c|c|c|c|c|c|c|}
\hline & & \multicolumn{7}{|c|}{ Sample } \\
\hline \multicolumn{2}{|c|}{ Temperature } & Fh7.5 & Fh22 & Fh50 & Fh75 & BC-11 & 2-Line ${ }^{b}$ & 6-Line ${ }^{b}$ \\
\hline \multirow[t]{3}{*}{$300 \mathrm{~K}$} & $\mathrm{~B}_{\mathrm{HF}}, \mathrm{T}$ & - & - & - & $33.3(1)$ & - & - & - \\
\hline & $\mathrm{QS}, \mathrm{mm} / \mathrm{s}$ & $0.78(1)$ & $0.75(1)$ & $0.72(1)$ & $-0.07(3)$ & $0.78(1)$ & 0.80 & 0.62 \\
\hline & IS, $\mathrm{mm} / \mathrm{s}$ & $0.34(1)$ & $0.36(1)$ & $0.35(1)$ & $0.37(1)$ & $0.34(1)$ & 0.35 & 0.35 \\
\hline \multirow{3}{*}{$4.2 \mathrm{~K}$} & $\mathrm{~B}_{\mathrm{HF}}, \mathrm{T}$ & $47.8(5)$ & $48.5(1)$ & 49.4(1) & $49.7(2)$ & 49.1(1) & 47 & 50 \\
\hline & $\mathrm{QS}, \mathrm{mm} / \mathrm{s}$ & $-0.02(1)$ & $-0.03(1)$ & $-0.04(1)$ & $-0.04(1)$ & $-0.04(1)$ & -0.02 & -0.07 \\
\hline & $\mathrm{IS}, \mathrm{mm} / \mathrm{s}$ & $0.43(1)$ & $0.46(1)$ & $0.46(1)$ & $0.47(1)$ & $0.55(1)$ & & \\
\hline
\end{tabular}

${ }^{a}$ Maximum hyperfine field $\left(B_{H F}\right)$, quadrupole splitting $(Q S)$, isomer shift $(I S)$. Errors are quoted within parentheses.

${ }^{\mathrm{b}}$ Murad and Cashion [2004]. 

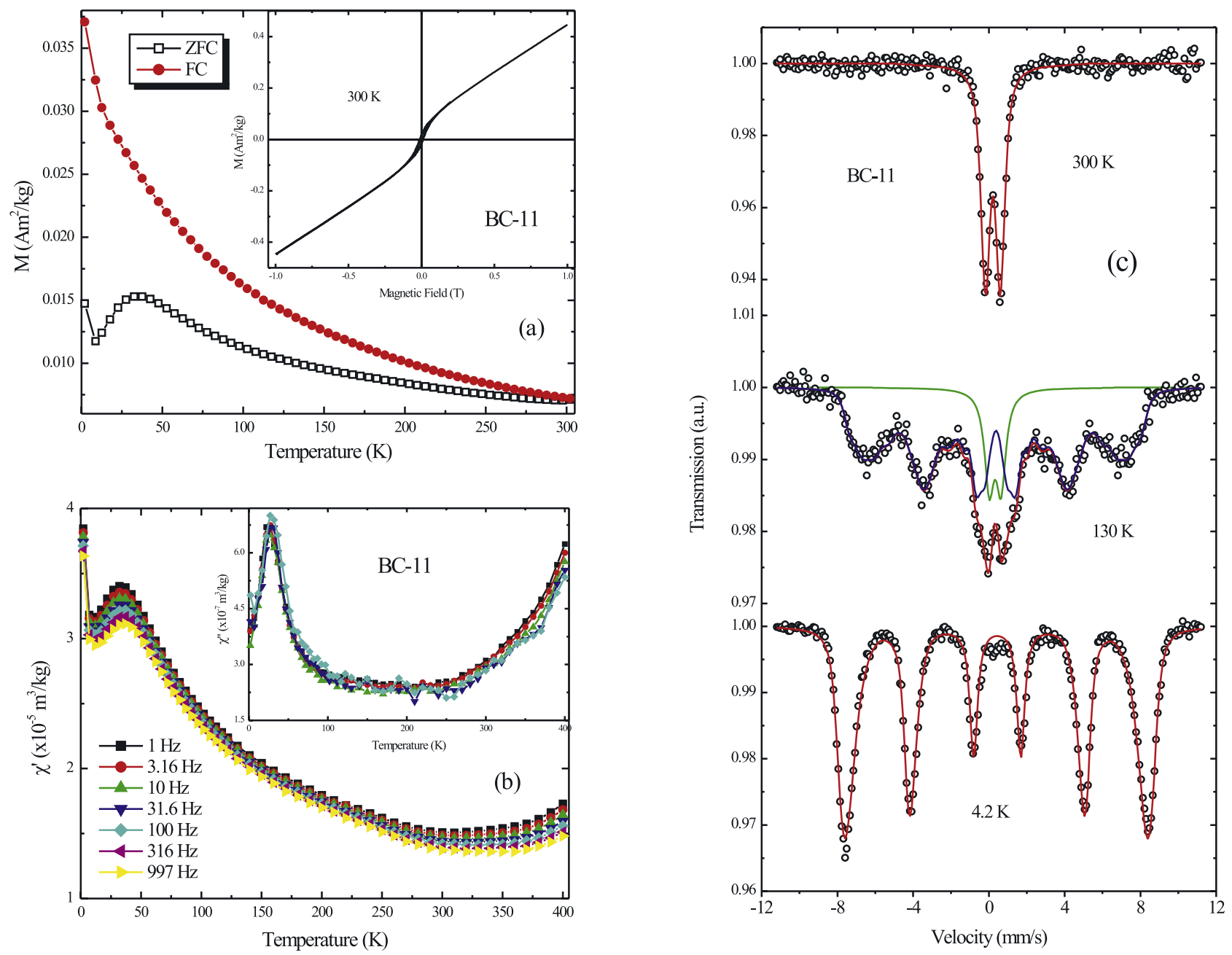

Figure 7. (a) ZFC/FC curves with applied field of $5 \mathrm{mT}$, inset: hysteresis loops at room temperature; (b) ac susceptibility in phase, inset: ac susceptibility out phase; (c) Mössbauer spectra at room temperature, $130 \mathrm{~K}$ and $4.2 \mathrm{~K}$ from natural ferrihydrite sample $(B C-11)$.

distribution. Furthermore, the out of phase susceptibility (Figure $7 \mathrm{~b}$ inset) increases from 300 to $400 \mathrm{~K}$ and beyond. This behavior is consistent with the presence of a large particle size fraction. It is the larger particles that are responsible for the lack of overlap between $\mathrm{ZFC}$ and $\mathrm{FC}$ curves. Interestingly, $B C-11$ and $F h 75$ share an important magnetic feature, hysteresis at room temperature (Figure $7 \mathrm{a}$ inset). This is strong evidence for behavior outside of the exclusively superparamagnetic threshold of the vast majority of ferrihydrite heretofore characterized. This is to say, the open hysteresis loops (displaying finite coercive force) are therefore related to the presence of a fraction of larger particles.

[25] Finally, Mössbauer spectra (Figure 7c) collected for $B C$-11 demonstrate thermally blocked magnetization at $4.2 \mathrm{~K}$, at $130 \mathrm{~K}$ two components corresponding to a doublet and sextet were fitted and at room temperature only a doublet, which signifies the superparamagnetic threshold. The hyperfine parameters fitted at $4.2 \mathrm{~K}$ corresponding to the sextet are in agreement with ferrihydrite and are close to the parameters found for sample Fh75 (particle size = $23 \mathrm{~nm}$ ). Interestingly, complete magnetic order (i.e., a sextet), which should be associated with the large particles at room temperature (and evident in all other types of magnetic data) is not present in the Mössbauer spectrum at $300 \mathrm{~K}$. Such a sextet was shown by the synthetic sample $F h 75$ at $300 \mathrm{~K}$. This feature could indicate that the fraction of large ferrihydrite is simply below the detection limit of Mössbauer spectroscopy. Another explanation worth considering is related to degree of agglomeration of natural ferrihydrite. Mørup et al. [2002] have presented evidence on the importance of agglomeration for nanophase hematite. In their work, they present Mössbauer spectra evolving from 4.2 $\mathrm{K}$ to room temperature of the same particle size with coated and uncoated surfaces. Interestingly, the Mössbauer spectra of $B C-11$ follow the same pattern as coated particles. We present the spectrum at $130 \mathrm{~K}$ (Figure $7 \mathrm{c}$ ) where the coexistence of a doublet and sextet is noticed instead of the collapsed magnetic hyperfine field typical of interacting particles. Mørup et al. [2002] show (in their Figure 1) that the Mössbauer spectra at room temperature have different patterns in the two cases, a doublet for coated and a sextet for uncoated samples. Also, they noted that a substantial decrease of temperature was necessary for onset of magnetic 


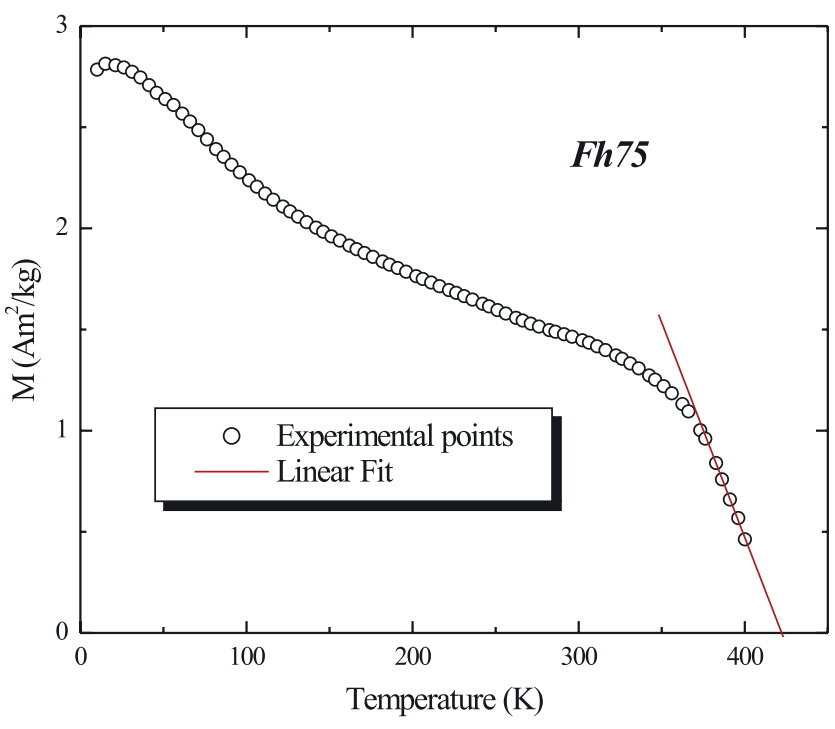

Figure 8. Induced magnetization curve (measure with $1 \mathrm{~T}$ magnetic field applied) showing the decrease of magnetization with temperature. At $400 \mathrm{~K}$ the sample carried only $17 \%$ of the initial induced magnetization. $T_{N}=422 \mathrm{~K}$ was obtained by extrapolation.

order for the coated sample when the doublet was the main feature. HRTEM of $B C$ - 11 ferrihydrite (Figure 2b) demonstrates that the particles are clearly in contact with one another. However, Mössbauer results suggest that the ferrihydrite nanoparticles are noninteracting. This interpretation is supported by the sextet and doublet superposition as observed for noninteracting particles. Thus we propose that the natural ferrihydrite nanoparticles have a core-shell structure in which the shell is enriched in $\mathrm{Si} / \mathrm{As}$, which could prevent magnetic interactions due to aggregation. However, a small fraction of the particles could be agglomerated, and in the presence of a large steady magnetic field ( $1 \mathrm{~T})$ they behave like larger particles and are also responsible for a finite coercive force displayed at $300 \mathrm{~K}$.

\section{Can We Determine Ferrihydrite Néel Temperature?}

[26] Since it was observed that $T_{B}^{\text {Main }}$ is above room temperature for sample $F h 75\left(d_{X R D}=23.6 \mathrm{~nm}\right)$ our natural inclination was to attempt to determine Néel temperature $\left(T_{N}\right)$, a very useful and intrinsic property to identify magnetic phases. For ferrihydrite, $T_{N}$ is not well known since relaxation effects due to small particle size are observed at low temperatures (in the range of $60 \mathrm{~K}$ and $150 \mathrm{~K}$ ). The usual superparamagnetic behavior could thus be misinterpreted as a paramagnetic state. The main source of information about ferrihydrite $T_{N}$ comes from fitting magnetization curves of ferritin using the Langevin model [Gilles et al., 2000]. The extrapolated temperatures obtained by other authors [e.g., Guyodo et al., 2006] claim the $T_{N}$ of synthetic ferrihydrite to be between $400 \mathrm{~K}$ and $500 \mathrm{~K}$. To the best of our knowledge, there is no experimental evidence obtained with larger size ferrihydrite where the behavior is not superparamagnetic but thermally stable at room temperature. In order to determine $T_{N}$ we cooled the $23 \mathrm{~nm}$ sample $(F h 75)$ from room temper- ature down to $5 \mathrm{~K}$ and then applied a magnetic field of $1 \mathrm{~T}$ to suppress effects of superparamagnetic particles. The induced magnetization was then measured with increasing temperature up to $400 \mathrm{~K}$. The data are presented in Figure 8 . We can see the slow magnetization decrease, and at our maximum experimental temperature of $400 \mathrm{~K}$, approximately $17 \%$ of the magnetization is still left, suggesting that $T_{N}$ is between 400 and $500 \mathrm{~K}$ for $F h 75$. Fitting a straight line with a constant slope for the final part of the curve provides an extrapolated $T_{N}$ of $422 \mathrm{~K}$ for our $\mathrm{Si}$-ferrihydrite. This temperature is in agreement within the temperature range estimated by Guyodo et al. [2006] although our $T_{N}$ may be slightly smaller due to Si-doping effects. It is worth remembering that the samples studied by Guyodo et al. [2006] were pure ferrihydrite. A similar effect of decrease of Curie temperature in a doped material is observed in other iron oxide phases like titanomagnetite [Cullity, 1972; O’Reilly, 1984].

\section{Conclusion}

[27] The magnetic characterization performed with these silicon-bearing ferrihydrites showed an important feature: ferrihydrite particle diameter depends on the synthesis temperature. Magnetic characterization, in combination with X-ray diffraction and HRTEM, demonstrates that the size of ferrihydrite particles produced by air oxidation of aqueous ferrous solution increases with increasing synthesis temperature. Sample $B C-11$ collected at a marine shallow-water hydrothermal system in Bahia Concepcion, Baja California, Mexico is an example of large natural ferrihydrite. The hydrothermal fluid temperature is around $88^{\circ} \mathrm{C}$ and the conditions (high temperatures and $\mathrm{Si}$ concentration) seem to favor the growth of such large ferrihydrite. Although large particle size may not be common in nature, the sample $B C$-11 presented a "7-line" XRD pattern as well as a signature for stable single domain particles, easily identified by open hysteresis loops. For all five samples, (synthetic and natural ferrihydrite) an important contribution of small particles with $T_{B}^{\text {Fine }}$ around $25 \mathrm{~K}$ was observed. Those small particles could reflect the presence of primary particles (or seeds) that may be related to the formation of the larger ferrihydrite particles. A synthetic sample (Fh 75) with large particle size, the seven-line silicon-doped ferrihydrite described here, yields an estimated $T_{N}$ of $422 \mathrm{~K}$. Our results suggest that very large crystallites of ferrihydrite could act as carriers of natural remanent magnetization, but it is improbable that particles smaller than $10 \mathrm{~nm}$ could. The rare occurrence of large particles means that ferrihydrite will not likely contribute to magnetic record. Other topics that need to be investigated in the future include ferrihydrite anisotropy constant since, for this material, there is not as reliable a value available as for other iron phases.

[28] Acknowledgments. This study was supported by National Science Foundation (NSF) grant EAR 0311869 from the Biogeosciences program and MRI EAR 0320641. Institute for Rock Magnetism (IRM) is funded by the Earth Science Division of NSF, the W. M. Keck Foundation and University of Minnesota. This is IRM publication 0508. The use of trade names does not imply endorsement. The U. S. Environmental Protection Agency through its Office of Research and Development funded a portion of the research described herein. It has not been subjected to Agency review and therefore does not necessarily reflect the views of the Agency, and no official endorsement should be inferred. 


\section{References}

Anderson, P. R., and M. M. Benjamim (1985), Effects of silicon on the crystallization and adsorption properties of ferric oxides, Environ. Sci. Technol., 19, 1048-1053.

Brown, G. (1980), Associated minerals, in Crystal Structures of Clay Minerals and their Identification, edited by G. W. Brindley and G. Brown, pp. 361-410, Mineral. Soc. London.

Campbell, A. S., U. Schwertmann, H. Stanjek, J. Friedl, A. Kyek, and P. A. Campbell (2002), Si incorporation into hematite by heating Si-ferrihydrite, Langmuir, 18, 7804-7809.

Carlson, L., and U. Schwertmann (1981), Natural ferrihydrites in surface deposits from Finland and their association with silica, Geochim. Cosmochim. Acta, 45, 421-429.

Chantrell, R. W., M. El-Hilo, and K. O'Grady (1991), Spin-glass behavior in a fine particle system, IEEE Trans. Mag., 27, 3570-3578.

Chasteen, N. D., and P. M. Harrison (1999), Mineralization in ferritin: An efficient means of iron storage, J. Struct. Biol., 126(3), 182-194.

Childs, C. W. (1992), Ferrihydrite: A review of structure, properties and occurrence in relation to soils, Z. Pflanzenernahr. Bodenk, 155, 441-448.

Cornell, R. M., and U. Schwertmann (2000), The Iron Oxides: Structure, Properties, Reactions, Occurrences and Uses, VCH, Weinheim, Germany.

Cullity, B. D. (1972), Introduction to Magnetic Materials, Addison-Wesley, Reading, Mass.

Dormann, J. L., D. Fiorani, and E. Tronc (1997), Magnetic Relaxation in Fine-Particle Systems, Adv. in Chem. Phys., vol. XCVIII, edited by I. Prigogine and S. A. Rice, pp. 283-494, John Wiley, Hoboken, N. J.

Drits, V. A., B. A. Sakharov, A. L. Salyn, and A. Manceau (1993), Structural model for ferrihydrite, Clay Minerals, 28, 185-208.

Fleischer, M., G. Y. Chao, and A. Kato (1975), New mineral names, Am. Mineral., 60, 485-486.

Friedman, J. R., U. Voskoboynik, and M. P. Sarachik (1997), Anomalous magnetic relaxation in ferritin, Phys. Rev. B, 56, 10,793-10,796.

Gider, S., D. D. Awschalom, T. Douglas, S. Mann, and M. Chaparala (1995), Classical and quantum magnetic phenomena in natural and artificial ferritin proteins, Science, 268, 77-80.

Gilles, C., P. Bonville, K. K. W. Wong, and S. Mann (2000), Non-Langevin behaviour of the uncompensated magnetization in nanoparticles of artificial ferritin, Eur. Phys. J. B, 17, 417-427.

Gilles, C., P. Bonville, H. Rakoto, J. M. Broto, K. K. W. Wong, and S. Mann (2002), Magnetic hysteresis and superparantiferromagnetism in ferritin nanoparticles, J. Magn. Magn. Mater., 241, 430-440.

Guyodo, Y., S. K. Banerjee, R. L. Penn, D. Burleson, T. S. Berquó, T. Seda and P. Solheid (2006), Magnetic properties of synthetic six-line ferrihydrite nanoparticles, Phys. Earth Plant. Int., 157, 222-233.

Hansen, M. F., and S. Mørup (1999), Estimation of blocking temperatures form ZFC/FC curves, J. Magn. Magn. Mater., 203, 214-216.

Harris, J. G. E., J. E. Grimaldi, D. D. Awschalom, A. Chiolero, and D. Loss (1999), Excess spin and the dynamics of antiferromagnetic ferritin, Phys. Rev. B, 60, 3453-3456.

Jambor, J. L., and J. E. Dutrizac (1998), Occurrence and constitution of natural and synthetic ferrihydrite, a widespread iron oxyhydroxide, Chem. Rev., 98, 2549-2585.

Jambor, J. L., N. N. Pertsev, and A. C. Roberts (1995), New mineral names, Am. Mineral., 80, 847.

Janney, D. E., J. M. Cowley, and P. R. Buseck (2000), Transmission electron microscopy of synthetic 2- and 6-line ferrihydrite, Clays Clay Minerals, 48, 111-119.

Janney, D. E., J. M. Cowley, and P. R. Buseck (2001), Structure of synthetic 6-line ferrihydrite by electron nanodiffraction, Am. Mineral., 86, $327-$ 335.

Jansen, E., A. Kyek, W. Schäfer, and U. Schwertmann (2002), The structure of six-line ferrihydrite, Appl. Phys. A, 74, S1004-S1006.

Kilcoyne, S. H., and R. Cywinski (1995), Ferritin: A model superparamagnet, J. Magn. Magn. Mater., 140-144, 1466-1467.

King, P. L., and H. Y. McSween Jr. (2005), Effects of $\mathrm{H} 2 \mathrm{O}, \mathrm{pH}$, and oxidation state on the stability of Fe minerals on Mars, J. Geophys. Res., 110, E12S10, doi:10.1029/2005JE002482.

Liu, Q., J. Torrent, B. A. Maher, Y. Yu, C. Deng, R. Zhu, and X. Zhao (2005), Quantifying grain size distribution of pedogenic magnetic particles in Chinese loess and its significance for pedogenesis, J. Geophys. Res., 110, B11102, doi:10.1029/2005JB003726.

Makhlouf, S. A., F. T. Parker, and A. E. Berkowitz (1997), Magnetic hysteresis anomalies in ferritin, Phys. Rev. B, 55, 14,717-17,420.

Mørup, S., C. Frandsen, F. Bødker, S. N. Klausen, P.-A. Lindgård, and M. F. Hansen (2002), Magnetic properties of nanoparticles of antiferromagnetic materials, Hyp. Inter., 144/145, 347-357.
Murad, E., and J. Cashion (2004), Mössbauer Spectroscopy of Environmental Materials and Their Utilization, Springer, New York.

O’Reilly, W. (1984), Rock and Mineral Magnetism, Blackie, Glasgow.

Pannalal, S. J., S. A. Crowe, M. T. Cioppa, D. T. A. Symons, A. Sturn, and D. A. Fowle (2005), Room-temperature magnetic properties of ferrihydrite: A potential magnetic remanence carrier?, Earth Plan. Sci. Lett. 236, 856-870.

Parfitt, R. L., S. J. Van der Gaast, and C. W. Childs (1992), A structural model for natural siliceous ferrihydrite, Clay Clay Minerals, 40, 675681

Penn, R. L. (2004), Kinetics of oriented aggregation, J. Phys. Chem. B, 108, $12,707-12,712$.

Pichler, T., J. Veizer, and G. E. M. Hall (1999a), The chemical composition of shallow-water hydrothermal fluids in Tutum Bay, Ambitle Island, Papua New Guinea and their effect on ambient seawater, Mar. Chem., 64(3), 229-252.

Pichler, T., J. Veizer, and G. E. M. Hall (1999b), Natural input of arsenic into a coral-reef ecosystem by hydrothermal fluids and its removal by Fe(III) oxyhydroxides, Environ. Sci Techn., 33, 1373-1378.

Punnoose, A., T. Phanthavady, M. S. Seehra, N. Shah, and G. P. Huffman (2004), Magnetic properties of ferrihydrite nanoparticles doped with $\mathrm{Ni}$, Mo, and Ir, Phys. Rev. B, 69, 054425.

Rancourt, D. G., D. Fortin, T. Pichler, P.-J. Thibault, G. Lamarche, R. V. Morris, and P. H. J. Mercier (2001), Mineralogy of a natural As-rich hydrous ferric oxide coprecipitate formed by mixing of hydrothermal fluid and seawater: Implications regarding surface complexation and color banding in ferrihydrite deposits, Am. Mineral., 86, 834-851.

Richmond, W. R., M. Loan, J. Morton, and G. M. Parkinson (2004), Arsenic removal from aqueous solution via ferrihydrite crystallization control, Environ. Sci. Technol., 38, 2368-2372.

Riveros, P. A., J. E. Dutrizac, and P. Spencer (2001), Arsenic disposal practices in the metallurgical industry, Can. Metal. Q., 40, 395-420.

Rodmacq, B. (1984), Superparamagnetic properties of small iron hydroxide preciptates in ion exchange membranes, J. Phys. Chem. Solids, 45 , $1119-1127$

Schwertmann, U., D. G. Schulze, and E. Murad (1982), Identification of ferrihydrite in soils by dissolution kinetics, differential X-ray diffraction, and Mossbauer spectroscopy, Soil Sci. Soc. Amer. J., 46, 869-875.

Schwertmann, U., J. Friedl, and A. Kyek (2004), Formation and properties of a crystallinity series of synthetic ferrihydrites (2- to 6-line) and their relation to $\mathrm{FeOOH}$ forms, Clay Clay Minerals, 52, 221-226.

Seehra, M. S., P. Roy, A. Raman, and A. Manivannan (2004), Structural investigations of synthetic ferrihydrite nanoparticles doped with $\mathrm{Si}$, Solid State Commun., 130, 597-601.

Stanjek, H., and P. G. Weidler (1992), The effect of dry heating on the chemistry, surface area, and oxalate solubility of synthetic 2-line and 6-line ferrihydrites, Clay Minerals, 27, 397-412.

St. Pierre, T. G., N. T. Gorham, P. D. Allen, J. L. Costa-Kramer, and K. V. Rao (2001), Apparent magnetic energy-barrier distribution in horsespleen ferritin: Evidence for multiple interacting magnetic entities per ferrihydrite nanoparticle, Phys. Rev. B, 65, 024436

Suzdalev, I. P., V. N. Buravtsev, V. K. Imshennik, Y. V. Maksimov, V. V. Matveev, S. V. Novichikhin, A. X. Trautwein, and H. Winkler (1996), Magnetic properties of ultrafine ferrihydrite clusters studied by Mössbauer spectroscopy and by thermodynamical analysis, Z. Phys. D, $37,55-61$.

Tejada, J., X. X. Zhang, E. del Barco, and J. M. Hernandez (1997), Macroscopic resonant tunneling of magnetization in ferritin, Phys. Rev. Lett. $79,1754-1757$

Towe, K. M., and W. F. Bradley (1967), Mineralogical constitution of colloidal "hydrous ferric oxides", J. Colloid Interface Sci., 24, 384-392.

Zergenyi, R. S., A. M. Hirt, S. Zimmermann, J. P. Dobson, and W. Lowrie (1999), Low-temperature magnetic behavior of ferrihydrite, J. Geophys. Res., 105, 8297-8303.

S. K. Banerjee and T. S. Berquó, Department of Geology and Geophysics, Institute for Rock Magnetism, University of Minnesota, 310 Pillsbury Drive SE, Minneapolis, MN 55455, USA. (berqu013@umn.edu)

R. G. Ford, National Risk Management Research Laboratory, U.S. Environmental Protection Agency, 919 Kerr Research Drive, Ada, OK 74820, USA.

R. L. Penn, Department of Chemistry, University of Minnesota, 207 Pleasant Street SE, Minneapolis, MN 55455, USA

T. Pichler, Department of Geology, University of South Florida, 4202 E. Fowler Avenue, SCCA 528, Tampa, FL 33620, USA 